\begin{abstract}
国
HOW BIG IS THE SPECULATIVE COMPONENT IN AUSTRALIAN SHARE PRICES
\end{abstract}

by

Angela Black

Patricia Fraser

And

Nicolaas Groenewold

DISCUSSION PAPER 01.14

DEPARTMENT OF ECONOMICS

THE UNIVERSITY OF WESTERN AUSTRALIA

35 STIRLING HIGHWAY

CRAWLEY, WA 6009

AUSTRALIA 


\title{
How Big is the Speculative Component in Australian Share Prices?
}

\author{
by
}

\author{
Angela Black, \\ Department of Accountancy and Finance, \\ University of Aberdeen, \\ Edward Wright Building, \\ Dunbar Street, \\ Aberdeen AB24 3QY \\ Scotland, UK \\ email: angela.j.black@abdn.ac.uk
}

\author{
Patricia Fraser, \\ Department of Accountancy and Finance, \\ University of Aberdeen, \\ Edward Wright Building, \\ Dunbar Street, \\ Aberdeen AB24 3QY \\ Scotland, UK \\ email: prof.p.fraser@.abdn.ac.uk \\ Nicolaas Groenewold, \\ Department of Economics, \\ University of Western Australia, \\ Crawley, WA 6009 \\ Australia \\ email: ngroenew@ecel.uwa.edu.au
}

September, 2001

**Corresponding author.

Patricia Fraser is the Aberdeen Asset Management Professor of Finance and Investment Management 



\begin{abstract}
Using 20 years of Australian quarterly data, this paper decomposes Australian share prices into their fundamental and speculative components. To do this we derive the fundamental share-price-output ratio and, hence, the fundamental share price from a restricted vector-autoregressive model relating the aggregate real share-price index to real output. Our estimations use different assumptions regarding shareholders' required real rate of return. Our results imply that a significant speculative component exists in share prices (around 10\% in mid-2000) and that share-price over/undervaluation has a life-span of around 4 years.
\end{abstract}

JEL Codes: C22, E0, E3, G1, G12 



\section{Introduction}

Both macroeconomists and finance specialists are giving increasing attention to the relationship between the stock market and the rest of the economy. There can be little doubt about the growing importance of the stock market from the point of view of the aggregate economy. For example, in Australia the ratio of stock-market capitalisation to GDP has more than doubled in the last 30 years - from less than 50\% in 1973 to over $100 \%$ in 2000.

Not only has the stock market increased in size relative to the real economy, but it appears that the inter-relationship between them has strengthened. It has long been recognised that the stock market incorporates information about the macroeconomy (see, e.g., Cochrane, 1999) and recently there has been widespread recognition that the influence is also in the opposite direction - events in the stock market are likely to have an impact upon the real economy. Recent pronouncements by the Governor of Australia's central bank indicate the importance of the state of the stock market in its evaluation of economic conditions which are part of process of formulating monetary policy - see Macfarlane (2001a, 2001b and 2001c).

The growing interest in the relationship between the stock market and the real economy has raised the subject of the relationship between actual and warranted or fundamental share prices. This leads us to ask the question: are observed share prices overvalued or undervalued for anything but very short periods of time and, if so, what is the extent of the over/undervaluation? Indeed, how can we tell whether share prices are over- or under-valued?

In practice, market participants and commentators have often expressed the view that stock market values deviate from their fundamentals and, at least in popular discussion, these views are often based on an examination of financial ratios such as 
the price-earnings ratio or the dividend-price ratio. ${ }^{1}$ This analysis is, however, mostly informal, being based on long-term average values of these ratios and the assumption that they are constant over long periods so that deviations from them are temporary and provide a basis for predictions of long-term share-price movements. The assumption that a particular financial ratio is constant in the long term is effectively a simple model of the fundamental share price and, typically, has no theoretical basis.

In this paper we approach the question of the fundamental share price within a modelling framework which captures the relationship between the share market and the real economy in a way that is broadly consistent with much theorising in financial economics. The procedure can be seen as an extension to the macroeconomic level of the work on the relationship between stock prices and dividends initiated by Campbell et al. (see Campbell and Shiller, 1987, 1988, 1989 and Campbell and Ammer, 1993) and also applied by Lee et al. (see Lee, 1995, 1998, Chung and Lee, 1998 and Hess and Lee, 1999).

We use a vector-autoregressive (VAR) model restricted by the theoretical predictions about the relationship of real share prices to output which can also be seen as an extension of the VAR approach to the modelling of this relationship. A relatively early application of the VAR model to the analysis of the relationship between stock prices and the macroeconomy is by Lee (1992) and more recent ones can be found in Cheung and $\mathrm{Ng}$ (1998) and Gjerde and Saettem (1999). In relation to the VAR approach to modelling the share-price-output relationship, our work can been seen as a version of the structural VAR first made popular by Blanchard and Quah (1989) in the empirical macroeconomics literature. In this literature VARs are restricted on the basis of theoretical considerations so as to make it possible to provide

\footnotetext{
${ }^{\prime}$ See Campbell and Shiller(1998) for a recent comprehensive examination of a range of financial ratios for the US stock market and the possible implications for future share prices.
} 
an economic interpretation to the shocks which drive the model, something that is not possible in standard VARs.

Our modelling requires an assumption about the nature of investors' required return and we experiment with three alternatives: that they are constant, that the riskfree rate component is time-varying and that the risk premium component is timevarying. The three alternative series that we obtain for fundamental share prices are broadly similar. They show that share prices deviate from their fundamentals for long periods of time - typically for four years - and that share prices at the end of our sample period (mid-2000) were about $10 \%$ above fundamentals.

We begin, in section 2 , by setting out the theoretical framework and deriving from it the restrictions to be imposed on our VAR model. We go on to use the restricted VAR to define the fundamental stock price as stock prices that are consistent with the model. We discuss the data used and preliminary statistics in section 3 . In section 4 we report the estimation results and we then use the estimated restricted model to compute a series for fundamental stock prices which are the stock prices warranted by the expected growth in output as generated by the restricted model. Conclusions are presented in section 5 . 


\section{The Model}

We begin by assuming that in the framework of efficient financial markets and wealth holders who have rational expectations, the real value of the representative firm, $V_{t}$, will be the expected value of its future real profits discounted at the real discount rate. Therefore, $V$ represents the real value of the firm.

Note that in contrast to the dividend-discount model common in undergraduate finance text books, we use profits rather than dividends. This reflects the view that for the economy as a whole (with which we will be concerned), profits contain more information about fundamentals than dividends. For example, the work of Ackert and Smith (1993) suggests that dividends are managed over time and may not capture all current information on macroeconomic fundamentals.

We assume that the representative firm uses two factors to produce output, according to Cobb-Douglas production technology. One factor, called labour, is a variable one which the firm buys in the labour market at a real wage $w$ and the other, which is called capital, is in fixed supply and owned by the firm. We assume that the firm operates in competitive product and labour markets so that both output prices and wages, and therefore the real wage, are taken as given. A profit-maximising firm will set the real wage equal to the marginal product of labour, which is proportional to average product so that the wage bill and therefore real profits are proportional to output:

$$
\text { real profits } s_{t}=Y_{t}-w_{t} L_{t}=Y_{t}-\gamma \cdot Y_{t}=(1-\gamma) \cdot Y_{t}
$$

where $Y$ represents real output, $w$ the real wage, $L$ employment and $\gamma$ is the exponent of employment in the production function. ${ }^{2}$

\footnotetext{
${ }^{2}$ Alternatives to the above structure are possible without losing the central property of the model that the wage bill is proportional to the value of output. Thus, as an alternative to perfect competition, if we have monopolistic competition of the type that is popular in the macro labour literature (see, e.g., Layard, Nickell and Jackman, 1991) and a homogeneous single-factor production function, the
} 
Hence the real value of the firm can be written:

$$
V_{t}=(1-\gamma) E_{t} \sum_{i=1}^{\infty}\left(\frac{1}{\prod_{j=1}^{i}\left(1+\rho_{t+j}^{*}\right)}\right) \cdot Y_{t+i}
$$

where $\rho_{t}^{*}$ is the real (possibly time-varying) rate of return required by shareholders.

Following the representative agent method, we assume equation (1) to hold for the economy as a whole and in our empirical work we use an aggregate stock-price index rather than market capitalisation as the variable on the left-hand side. This involves the assumption of a constant relationship between the real stock-price index, $P$, and market capitalisation, $V$. Moreover, the application of (1) to the whole economy involves a further constancy assumption about the relationship between the value of all firms (to which $Y$ applies) and those covered by the index. These two constancy assumptions are therefore maintained in the empirical work that follows and failure of the model could result from the failure of one or both of these assumptions rather than the failure of the rational-valuation model. However, given that we use quarterly data and that our sample period is relatively short, these ratios are unlikely to vary substantially in practice - most of the variation in $\mathrm{V}$ reflects fluctuations in $\mathrm{P}$ and index coverage changes infrequently.

We therefore assume that the stock-price index is proportional to market capitalisation:

$$
P_{t}=\beta^{\prime} \cdot V_{t}
$$

Hence, defining $\beta=\beta^{\prime}(1-\gamma)$ and $Q_{t}=\beta . Y_{t}$, equation (1) can be re-written as:

proportionality result continues to hold although the constant of proportionality involves the elasticity of demand as well as the production parameter. On the labour-market front it is possible to introduce efficiency wages and the proportionality relationship continues to hold as long as the production function is homogeneous in labour in efficiency terms. Similar results can be obtained from a unionbargaining model. The convenient property that factor payments are proportional to output is not restricted to the Cobb-Douglas production function. It holds for all homothetic function such as the CES and the generalised CES production functions. 


$$
P_{t}=E_{t} \sum_{i=1}^{\infty}\left(\frac{1}{\prod_{j=1}^{i}\left(1+\rho_{t+j}^{*}\right)}\right) \cdot Q_{t+i}
$$

This equation is the basis for the computation of our fundamental stock-price index.

In order to use this we need to forecast output and the discount rate for which we use a linearised version of the model obtained using a method similar to that of Campbell and Shiller (1987). First, we define the time stream of real realised discount rates, $\rho_{t}$, to satisfy:

$$
P_{t}=\sum_{i=1}^{\infty}\left(\frac{1}{\prod_{j=1}^{i}\left(1+\rho_{t+j}\right)}\right) \cdot Q_{t+i}
$$

It follows that

$$
\left(1+\rho_{t+1}\right)=\left(P_{t+1}+Q_{t+1}\right) / P_{t}
$$

Taking logs and using lower case letters to represent the logs of their upper-case counterparts, we can write:

$$
r_{t+I}=\ln \left(1+\exp \left(q_{t+1}-p_{t+1}\right)\right)+p_{t+I}-p_{t}
$$

where $r$ is defined as $\ln (1+\rho)$ and $(q-p)$ is the economy-wide log "dividend-price ratio". The first term in (5) can be linearised using a first-order Taylor's approximation and (5) can then be written as:

$$
r_{t+1}=-\left(p_{t}-q\right)+\mu\left(p_{t+1}-q_{t+1}\right)+\Delta q_{t+1}+k
$$

where $k$ and $\mu$ are linearisation constants:

$$
\begin{aligned}
& \mu=1 /(1+\exp \overline{(q-p)}) \\
& k=-\ln \mu-(1-\mu) / \overline{(q-p)}
\end{aligned}
$$

where $\overline{(q-p)}$ is the sample mean of $(q-p)$ about which the linearisation was taken. Clearly, $0<\mu<1$ and in practice is close to 1 . 
Empirically it is common that both $p$ and $q$ are I(1) so that in the applications of this model the variables are transformed to ensure stationarity. Denote by $\pi$ the (log) stock-price-output ratio, $p-q$, and rewrite equation (6) as:

$$
\pi_{t}=k+\mu \pi_{t+1}+\Delta q_{t+1}-r_{t+1}
$$

After repeated substitution for $\pi_{t+1}, \pi_{t+2}, \ldots$ on the right-hand side of (7), we get:

$$
\pi_{t}=\frac{k\left(1-\mu^{i}\right)}{(1-\mu)}+\sum_{j=0}^{i-1} \mu^{i} \Delta q_{t+j+1}-\sum_{j=0}^{i-1} \mu^{i} r_{t+j+1}+\mu^{i} \pi_{t+i}
$$

Letting $i \rightarrow \infty$ and assuming that the limit of the last term is 0 , results in the following alternative form of (8):

$$
\pi_{t}=\frac{k}{(1-\mu)}+\sum_{j=0}^{\infty} \mu^{i} \Delta q_{t+j+1}-\sum_{j=0}^{\infty} \mu^{i} r_{t+j+1}
$$

Hence, if $q_{t} \sim \mathrm{I}(1)$ then $\Delta q_{t} \sim \mathrm{I}(0)$ and, assuming that $r_{t} \sim \mathrm{I}(0)$ (recall that it is the real discount rate), then $\pi_{t}$ will be $\mathrm{I}(0)$ and we have the model linearised and expressed in terms of stationary variables. Finally, taking conditional expectations of both sides:

$$
\pi_{t}=\frac{k}{(1-\mu)}+\sum_{j=0}^{\infty} \mu^{i} E_{t} \Delta q_{t+j+1}-\sum_{j=0}^{\infty} \mu^{i} E_{t} r_{t+j+1}
$$

where we interpret $E_{t^{r}+j+l}$ as shareholders' required return.

In order to use (10) to generate a series for $\pi^{*}$, the price-output ratio implied by the model and from it the implied or fundamental stock price, $p^{*}$, we need to obtain empirical counterparts to the terms on the right-hand side involving expectations. For the first of these, the expectation of output growth, we follow Campbell and Shiller (1987) and use a VAR model while for the second, the shareholders' required return, we make three alternative assumptions and assess the sensitivity of our fundamental stock-price series to these alternatives.

We begin with the simplest case and assume that the rate of return required by shareholders is constant and equal to $r$. In that case (10) becomes: 


$$
\pi_{t}=\frac{k-r}{(1-\mu)}+\sum_{j=0}^{\infty} \mu^{i} E_{t} \Delta q_{t+j+1}
$$

Next, we assume expected output growth to be generated by a VAR in the priceoutput ratio and output growth. Define the vector $z_{t}=\left(\pi_{t}, \Delta q\right)^{\prime}$ so that the VAR may be written as:

$$
z_{t+l}=A z_{t}+\varepsilon_{t+I}
$$

where $A$ is a (2x2) matrix of coefficients and $\varepsilon$ is a vector of error terms. We assume a lag length of 1 for ease of exposition. If, in the empirical application, a longer lag length is required, the companion form of the system can be used. Using the VAR for forecasting allows us to replace expected output growth by:

$$
E_{t} \Delta q_{t+j+l}=e_{2} A^{j+1} z_{t}
$$

Where $e_{2}$ is the second unit vector. Hence the value of $\pi_{t}$ generated by the combination of the present-value model and the forecasting assumptions (denoted $\pi^{*}$ ) is:

$$
\pi_{t}^{*}=\frac{k-r}{1-\mu}+\mathbf{e}_{2}^{\prime} \mathbf{A}\left(\mathbf{I}+\mu \mathbf{A}+\mu^{2} \mathbf{A}^{2}+\ldots\right) \mathbf{z}_{t}=\frac{k-r}{1-\mu}+\mathbf{e}_{2}^{\prime} \mathbf{A}(\mathbf{I}-\mu \mathbf{A})^{-1} \mathbf{z}_{t}
$$

which is the equation we use to generate $\pi^{*}$ and hence the fundamental stock price series once we have estimated the VAR coefficients and the constants $\mu, k$, and $r$. Given that we wish to generate a series for stock prices which are warranted by (predicted) output growth, we simply generate (the log of) fundamental stock prices as:

$$
p_{t}^{*}=\pi_{t}^{*}+q_{t}
$$

Equation (12) can also be used to derive tests of the model's ability to explain actual stock prices. This is simply a test of $\pi_{t}=\pi_{t}^{*}$ for all t. Since $\pi_{t}=e_{1} \xi_{t}$ where $e_{l}$ is the first unit vector, we can write (12), after transforming the variables to deviations from their means to remove the constant term, as: 


$$
e_{1}^{\prime} z_{t}=e_{2}^{\prime} A(I-\mu A)^{-1} z_{t}
$$

For this to hold for all $\mathrm{t}$ we require:

$$
e_{1}^{\prime}=e_{2}{ }^{\prime} A(I-\mu A)^{-I}
$$

which constitutes a set of non-linear restrictions on the coefficients of the VAR. They can be tested using the "delta method" (see Campbell, Lo and MacKinlay, 1997, p.540) which is based on writing equation (14) as

$$
\pi_{t}^{*}=k^{\prime} z_{t}
$$

where $\boldsymbol{k}^{\prime}=\left(k_{1}, k_{2}\right)=\boldsymbol{e}_{2}{ }^{\prime} \boldsymbol{A}(I-\mu A)^{-1}$ so that a test of $\pi_{t}=\pi_{t}^{*}$ is equivalent to a test of $\boldsymbol{k}=$ $\boldsymbol{e}_{1}$ which can be tested using the Wald statistic:

$$
\text { Wald } \left.=\left(k-e_{l}\right) !(\partial k / \partial A) \Omega(\partial k / \partial A)\right]\left(k-e_{l}\right)
$$

where $\Omega$ is the variance-covariance matrix of the VAR coefficients and the matrices of the partial derivatives of $\boldsymbol{k}$ with respect to the elements of $\boldsymbol{A}$ are evaluated at the estimated value of $\boldsymbol{A}$ and can be computed numerically. Under the hypothesis that the model is true, the Wald statistic is asymptotically $\chi^{2}$-distributed with 2 degrees of freedom.

All the above has been derived on the basis of the assumption that the real return required by wealth-holders is constant. We now relax this assumption in two alternative models. Both are based on the inter-temporal CAPM model of equilibrium returns due to Merton (1973, 1980), whereby the return required by shareholders is divided into a risk-free component and a risk premium.

In the first of the two alternatives we assume that the risk-free rate is timevarying but the risk premium is constant while in the second this assumption is reversed: the risk-free rate is assumed constant while the risk-premium is allowed to vary. Accommodating a time-varying risk-free rate is analogous to allowing changes in the rate of interest that equates individuals inter-temporal demand and supply of funds - the discount rate - while the inclusion of a time-varying risk premium can be explained in terms of 'habit persistence'. Campbell and Cochrane (1999) explain the 
latter in terms of business cycle risk: as we enter a recession, current consumption will fall toward the level of the habit and individual risk aversion will start to increase affecting future returns, which in turn, will be expected to rise. Conversely, in expansionary times, consumption will rise above the habit, risk aversion will decline and, vis-à-vis the risk premium, expected future returns will fall.

We decompose the real required return into the real risk-free rate, $f$, and a real risk premium, $\theta$ :

$$
E_{t} r_{t+j}=E_{t} f_{t+j}+E_{t} \theta_{t+j}
$$

In the case where the risk premium is constant we have:

$$
E_{t} r_{t+j}=E_{t} f_{t+j}+\theta
$$

and the expression for $\pi_{t}$, equation (10), becomes:

$$
\pi_{t}=\frac{k-\theta}{(1-\mu)}+\sum_{j=0}^{\infty} \mu^{i} E_{t} \Delta q_{t+j+1}-\sum_{j=0}^{\infty} \mu^{i} E_{t} f_{t+j+1}
$$

Clearly, once we have removed the constant from this equation by using variables in terms of deviations from their means, this is formally equivalent to the case where the required return is time-varying in an unrestricted way - in the empirical application they would be distinguished only by the data used for $r$ and $f$.

In this version of the model we use a three-variable VAR in $\pi, \Delta q$, and $f$ and use it to forecast both the last two variables. Re-define $z_{t}$ as $\left(\pi_{t}, \Delta q_{t}, f_{t}\right)^{\prime}$ and use it to forecast both $\Delta q$ and $f$ :

and

$$
E_{t} \Delta q_{t+j+1}=e_{2} A^{j+1} z_{t}
$$

so that in this case we compute the fundamental value of the $\log$ price-output ratio from:

$$
\pi_{t}^{*}=\frac{k-r}{1-\mu}+\left(\mathbf{e}_{2}^{\prime}-\mathbf{e}_{3}^{\prime}\right) \mathbf{A}(\mathbf{I}-\mu \mathbf{A})^{-1} \mathbf{z}_{t}
$$


We again use (13) to compute fundamental stock prices and, as in the previous case, the model's ability to explain actual stock prices can be tested as the hypothesis that $\pi_{t}$ $=\pi_{l}^{*}$ for all $\mathrm{t}$ which requires that

$$
e_{l}^{\prime}=\left(e_{2}{ }^{\prime}-e_{3}\right) A(T-\mu A)^{-1}
$$

in linear form. The first can be tested using the delta method as before while the second can be tested using a standard Wald test.

The second alternative to the constant-required-return model is one with a constant risk-free rate but a time varying risk premium. Here we follow the empirical work of Cuthbertson et al. (1997) and model the time varying risk premium as the product of the coefficient of relative risk aversion, $\alpha$, and the variance of returns, $\sigma_{t}$. The equation for the price-output ratio then becomes:

$$
\pi_{t}=\frac{k-f}{(1-\mu)}+\sum_{j=0}^{\infty} \mu^{i} E_{t} \Delta q_{t+j+1}-\alpha \sum_{j=0}^{\infty} \mu^{i} E_{t} \sigma_{t+j+1}^{2}
$$

In this case we forecast both real output growth and the return variance using a three variable VAR in $z_{t}=\left(\pi_{t} \Delta q_{t}, \sigma^{2}\right)^{\prime}$. The equation from which we compute the fundamental price-output ratio (and hence the fundamental stock price) is similar to equation (21):

$$
\pi_{t}^{*}=\frac{k-f}{1-\mu}+\left(\mathbf{e}_{2}^{\prime}-\alpha \mathbf{e}_{3}^{\prime}\right) \mathbf{A}(\mathbf{I}-\mu \mathbf{A})^{-1} \mathbf{z}_{t}
$$

and the restrictions that the model explains actual stock prices are similar to those in the previous case:

$$
e_{1}^{\prime}=\left(e_{2}{ }^{\prime}-\alpha e_{3}\right) A(I-\mu A)^{-I}
$$




\section{Data and Preliminary Statistics}

We use quarterly Australian data for the period March 1980 to June 2000. All data were taken from the Reserve Bank of Australia (RBA) Bulletin section of the $\mathrm{dX}$ EconData database. Financial data consist of the All Ordinaries share price and accumulation indices and the Australian 90-day Bank-Accepted Bill rate. The model set out in the previous section requires the share price index to be in real form and also requires a real rate of return. We experimented with three alternative deflators: the CPI, the GDP deflator and the private consumption deflator. All gave very similar real share-price indexes and we proceeded in our empirical work only with the index deflated by the CPI share price index. Output data used were GDP (expenditure definition) in $1997 / 98$ prices.

In the empirical work below, real output data is scaled so that the (log) realstock-price-output ratio, $\pi_{t}$, has the same dimension as the $(\log )$ real-stock-pricedividend ratio. The scale factor is calculated as: $\left((1+R) \cdot P_{t-1}-P_{t}\right) / Y_{t-1}$ where, $R$ is the real required rate of return of wealth-holders, $P_{t}$, is the value of the All Ordinaries index at time $t$, and $\mathrm{Y}_{\mathrm{t}-1}$, is lagged real output. The value of $\mathrm{R}$ is calculated as the sample average quarterly change in the real accumulation index. The (log) of the product of the scale variable and real output gives a time series of real output of the same dimension as those of dividends and is denoted $q_{t}$.

The variables included in the VAR models specified above in section 2 were constructed as follows. The All Ordinaries price index was used to calculate the (log) price-(scaled) output ratio $(\pi)$, while output growth over the sample period was measured as the change in (log) (scaled) output $\left(\Delta q_{t}\right)$. The risk-free rate was measured as the continuously compounded quarterly return from the 90-day bill rate

$\left(f_{t}\right)$. The variance $\left(\sigma_{t}^{2}\right)$ used in the model with a time-varying risk premium was 
measured simply as the squared deviation of the real return from its mean (and a dummy variable for the December 1987 quarter), the real return being computed from the deflated accumulation index. In earlier work we also experimented with a GARCH-generated variance series but found it made little difference to the final results. The restrictions imposed on the time-varying risk model also require a measurement of the CRRA, $\alpha$. This we calculate as $[A V E+(X R V A R / 2)] / X R V A R$, where $A V E$ is the mean return calculated from the accumulation index in excess of the risk-free rate and $X R V A R$ is the variance of these excess returns (see, Campbell and Shiller (1989) and Campbell et al. (1997)). All variables in the VAR are in terms of deviations from their sample mean thus avoiding the necessity of including a constant term in the VAR equations.

\section{Table 1 near here}

Table 1 provides summary statistics for the data used as well as for the generated variables used in the model. The returns to shares averaged around $9 \%$ pa counting just capital gains $(\Delta \ln (\mathrm{AOP}))$ or $13 \%$ if dividends are also included $(\triangle \ln (\mathrm{AOA}))$. The standard deviation was approximately three to four times the return. Inflation averaged about $5 \%$ pa over the sample but with lower variability than the share returns. The average annual return to 90 -day bills was $11 \%$ with a much lower variance than share returns. The mean bill rate is unusually high relative to recent experience and is accounted for by the fact that the sample includes the 1980s when the bill rate peaked at over $20 \%$ and averaged around $15 \%$. Thus, ignoring covariance risk, bills seem, in retrospect, to have been very competitive with shares. The real economic growth rate averaged just under $4 \%$ pa.

The returns based on the AOP and AOA indexes have properties common to financial asset returns - they are free of autocorrelation, as shown by the Box-Pierce- 
Ljung portmanteau statistics for first- to fourth-order autocorrelation $(\mathrm{Q}(4))$ but show marked non-normality, as evidenced by the Jarque-Bera (J-B) statistics; the source of the non-normality seems to be excess-kurtosis. Inflation and the 90-day bill rate both show very strong evidence of autocorrelation with large and slowly-declining autocorrelation coefficients; the inflation rate shows no sign of non-normality but the bill rate has a large and significant J-B statistic. The real versions of the stock return variables based on deflated share-price indexes, RAOA and RAOP, share the statistical properties of their nominal counterparts. The real GDP growth rate shows little evidence of either autocorrelation or non-normality. The three variables generated for the VAR model, $V, \pi$ and $\Delta \mathrm{q}$, show some autocorrelation and, in the case of $\Delta \mathrm{q}$, some non-normality.

The model is based on the assumption that $p$, the log of the real share price index, and $\mathrm{q}$, the $\log$ of real adjusted output, are non-stationary but cointegrated. Before estimating the model, therefore we tested these assumptions. Table 2 reports augmented Dickey-Fuller (ADF) statistics for both these variables. ${ }^{3}$

\section{Table 2 near here}

Clearly, both variables are non-stationary. The test outcome is not sensitive to presence of a trend in the Dickey-Fuller equation and is not sensitive to the number of lags in the equation. We therefore proceed to an analysis of cointegration. We report the results of the application of the Johansen trace and maximum-eigenvalue tests in Table $3 .^{4}$

\section{Table 3 near here}

The test statistics are reported for various cases depending on the number of lags in the VAR model used to compute the statistics and on whether the model

\footnotetext{
${ }^{3}$ See Dickey and Fuller (1981).
} 
included a time trend. In almost all cases the outcome is that the two variables are cointegrated although this conclusion is stronger when a trend is included in the model. Table 3 also reports the cointegrating vector in each case and it can be seen that when there is no trend in the equation the cointegrating vector is very close to the theoretically predicted one of $(1,-1)$. We therefore conclude that the requirements of the model that $\mathrm{p}$ and $\mathrm{q}$ are cointegrated in the special sense that their difference is stationary is satisfied and proceed to test the stationarity of the four variables used in the various versions of the VAR model: $\pi(=p-q), \Delta q, f$ and $V$. The results of these tests are reported in Table 4.

\section{Table 4 near here}

The results shown in Table 4 are clear for all but $\pi$. All of $\Delta q, f$ and $V$ are stationary although for $f$ this is unambiguous only at short lags. The case for $\pi$ is less clear. If there is no trend in the equation $\pi$ is stationary at lags 1 and 3 at the $5 \%$ level of significance and at $15 \%$ it is stationary at lags 2 and 4 . When a trend is included in the testing equation, it is not stationary at any lag; this, however, is not surprising given the nature of the cointegrating vector for $p$ and $q$ when a trend is used as reported in Table 3. We conclude that there is sufficient evidence of the stationarity of $\pi$ to warrant estimating the model as specified in section 2 .

\footnotetext{
${ }^{4}$ See Johansen (1988) and Johansen and Juselius (1990).
} 


\section{Empirical Results}

We now turn to the estimation and simulation of the model, beginning with the version based on the assumption of a constant required return.

\subsection{The model with constant required return}

Recall that the model in this case consists of two equations in $\pi$ and $\Delta q$. We set out the estimated model and tests of the model restrictions in Table 5.

\section{Table 5 near here}

For both equations in the VAR model, the $Q$ statistic indicates that residual autocorrelation is not a problem so that the single lag imposed on the system captures all relevant information on the variables in the VAR. With a $t$-statistic of 14.5 , the own lag on the price-output ratio appears to drive this variable, the lag of $\Delta q$ being insignificant. While the reported $\mathrm{R}^{2}$ is considerably less for the GDP growth equation than that for the price-output ratio equation, in the former we report coefficient estimates and significance levels and which suggests that the price-output ratio Granger causes output growth - the price-output variable has a $t$-statistic of 3.17 . We find no statistical evidence supporting the own lag of output growth in its data generating process. The Wald statistic indicates that the restrictions implied by the model are convincingly rejected suggesting that the actual and fundamental share prices series are significantly different.

Finally, we use the model to generate the fundamental share-price index as the share price which satisfies the present-value model restrictions and the VAR forecasting assumptions. This series, $p^{*}$, together with the observed share price index, $p$, for the period is plotted in Figure 1 . 


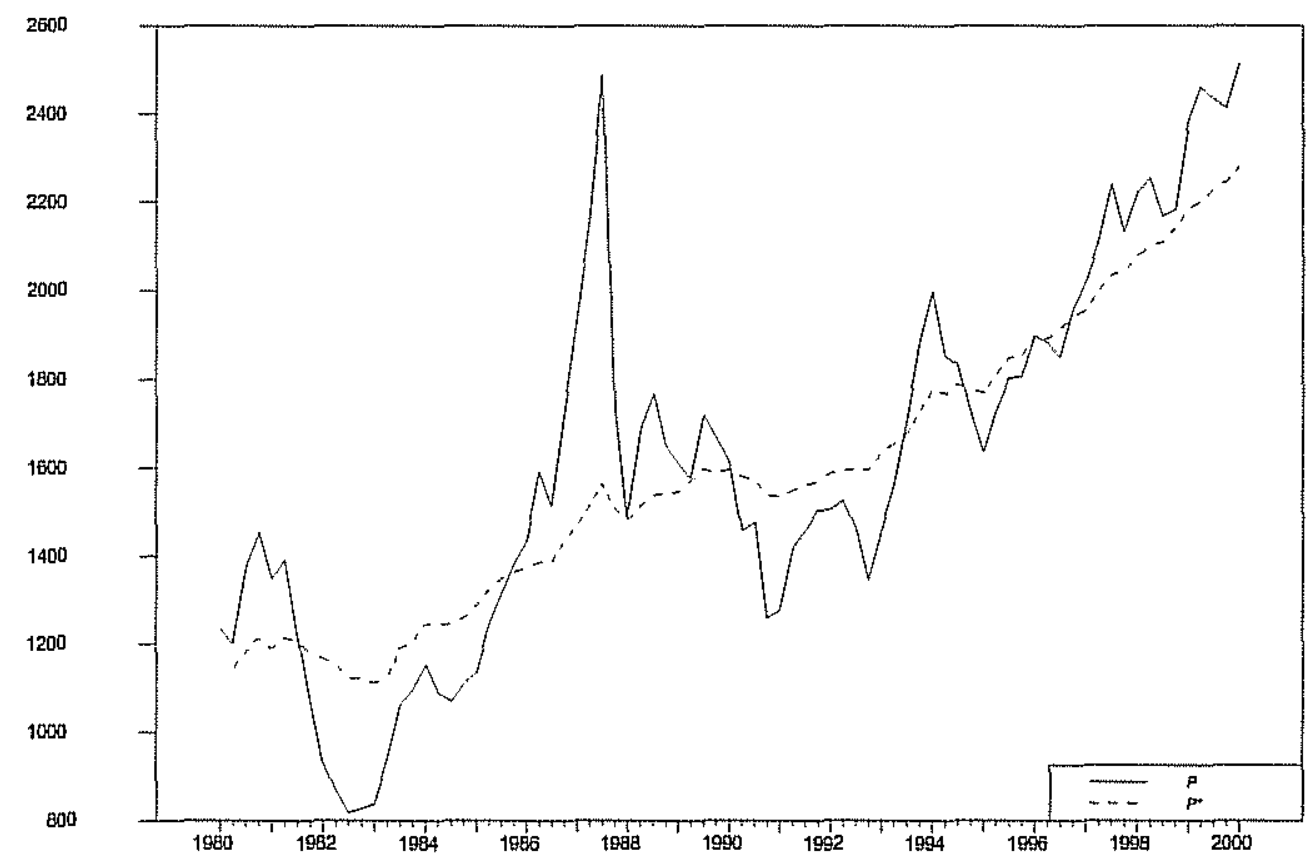

Figure 1. Actual and Fundamental Share Prices: Constant Required Rate of Return Model

As we would expect, the fundamental share-price series is considerably less volatile than the observed series. It shows that actual share prices fluctuate about their fundamental levels with long cycles of about 8 years' duration - prices are above fundamentals for about four years and then below for about the same length of time. At the end of the sample period, mid-2000, actual share prices were about $10 \%$ in excess of fundamentals.

The analysis of fundamental stock prices presented above however, is based on the assumption that the return required by wealth holders is constant. In practice the return may well vary over time and, as discussed earlier, time variation can come from two sources: time-variation in the risk-free rate and a time-varying risk premium. Consider the case of a time-varying risk-free rate first. 


\subsection{The Tine-Varying Risk-Free Rate Present Value Model}

The OLS estimates and tests for this model are presented in Table 6.

\section{Table 6 near here}

A comparison of the results for the first two equations with those reported in Table 5, shows that the introduction of the time-varying risk-free rate has little effect on the explanatory power for the first two variables. The equation for the price-output ratio is dominated by its own predictive power, while output growth remains influenced by those of the price-output ratio and also the risk-free rate. However, the risk-free rate has no predictive power for the price-output ratio and is itself influenced solely by its own lagged value. There does not appear to be significant autocorrrelation in the residuals of the first two equations although the equation for the risk-free rate is not entirely free of this problem. The Wald test again rejects the restrictions implied by the model indicating a significant difference between the actual and fundamental share prices. Figure 2 plots the actual and fundamental shareprice series from this model. 


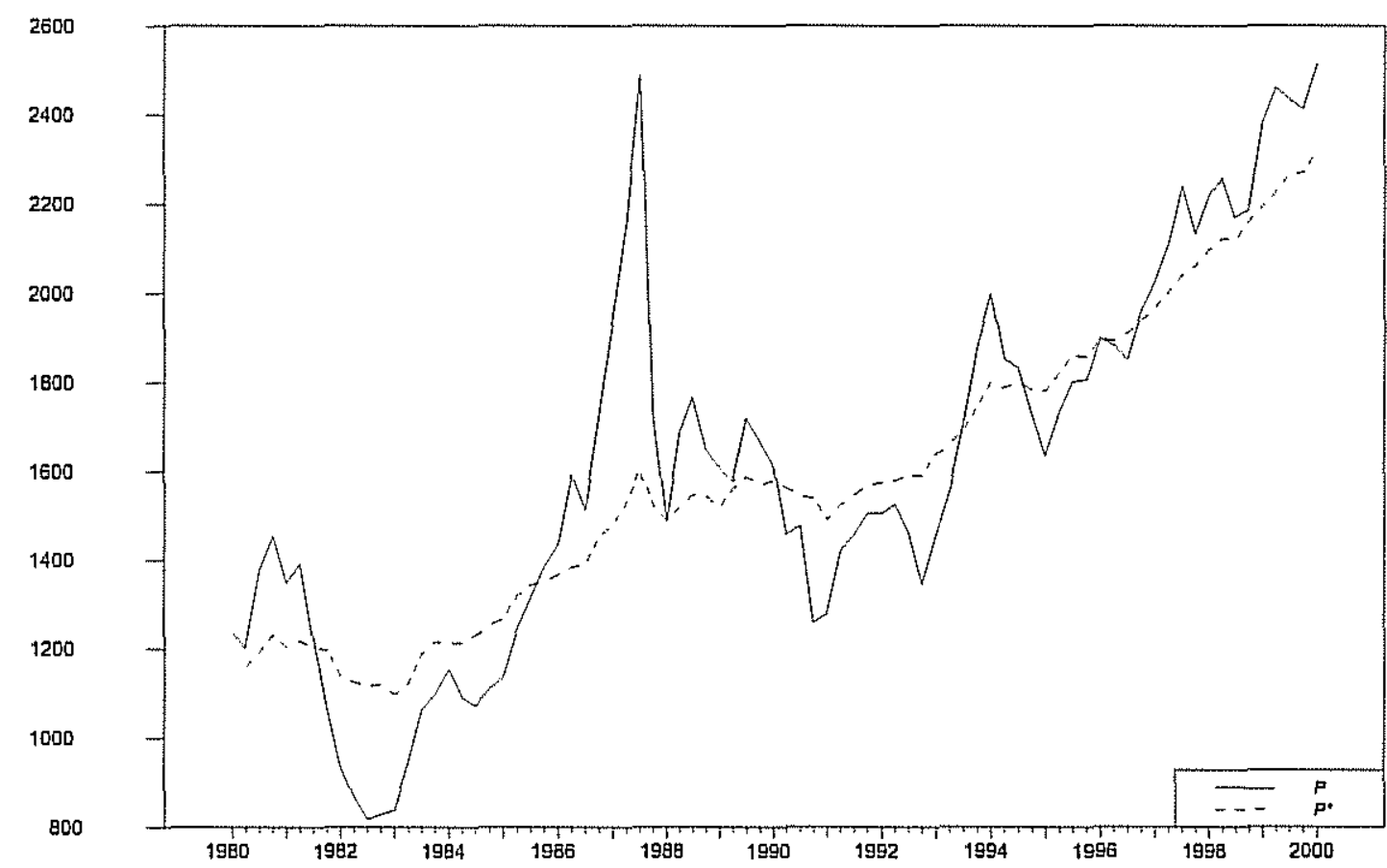

Figure 2. Actual and Fundamental Share Prices: Time-Varying Risk-

Free Rate Model

The graph bears out the message of the results in Table 6, that the addition of timevariation in the risk-free rate as part of investors' required rate of return affects the model only very little. The shape of the fundamental share-price series in Figure 2 is very similar to that in Figure 1 and conveys the same message.

Comparing Figures 1 and 2 as well as the statistics discussed above, leads us to conclude that a time-varying discount rate has no appreciable role to play in explaining the apparent gap between actual and fundamental stock prices. We, therefore, turn to the third formulation of the model which allows the required rate of return to vary by incorporating a variable risk premium while keeping the risk-free rate constant. 


\subsection{The Time-Varying Risk Present Value Model}

Table 4 reports the estimates and tests for the time-varying risk model discussed in Section 2 of this paper.

\section{Table 7 near here}

Clearly, the lagged time-varying risk proxy - the market variance variable - has predictive power for the price-output ratio but has no significant predictive power for either itself or output growth. Overall, this model implies one-way, negative causality leading from market risk to the price-output ratio: the coefficient estimates suggest that if the previous quarter's variance increases then the price-output ratio will decrease.

According to the $\mathrm{Q}$ statistic, the lag-length is adequately specified to capture autocorrelation up to the fourth order. The CRRA, computed as described in section 3 above, of 1.1235 lies within the empirically acceptable bounds of between 1 and 10 . While the $\mathrm{R}^{2}$ for the price-output ratio equation is larger than that reported for the same equation in Table 6, for the output growth equation and the variance equation the $\mathrm{R}^{2}$ is relatively smaller than those reported for the same equations in Table 3 using $f_{\mathrm{t}}$. The inferiority of the time-varying risk model is also reflected in the much larger Wald statistic for the overall restrictions of the model.

Figure 3 display the plot of the actual and fundamental price-output ratio series and the actual and fundamental price series generated from the time-varying risk-premium model. 


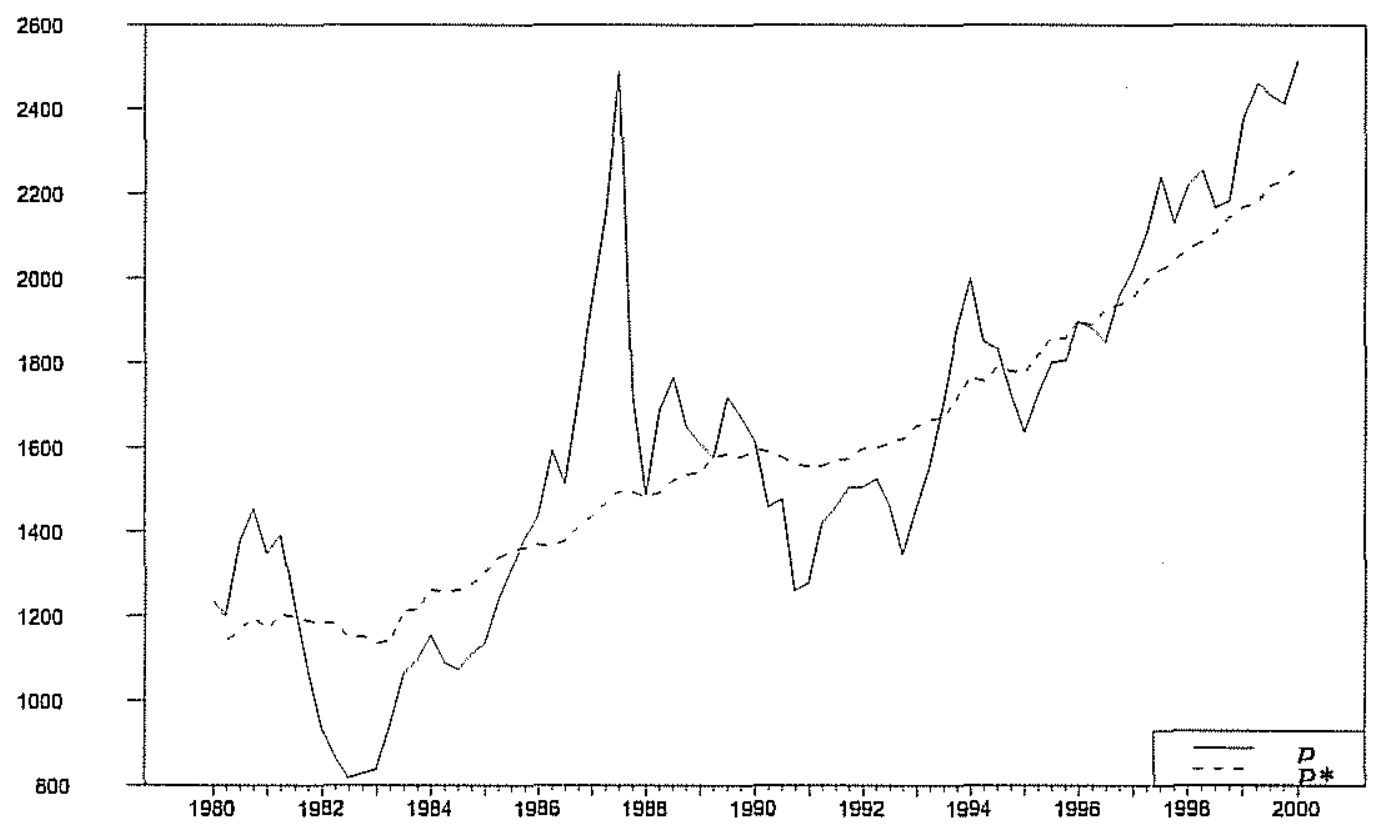

Figure 3. Actual and Fundamental Share Prices: Time-Varying Risk

Premium Model

The message from this graph is similar to that from the previous two, both in terms of the length and severity of cycles of actuals about fundamentals and in terms of the over-valuation of share prices by about $10 \%$ at the end of the sample period in mid2000 . 


\section{Conclusion}

This paper has explored the distinction between observed and fundamental share prices and used 20 years of Australian data to assess the empirical magnitude and significance of difference between the two measures. We observed that policymakers and others are increasingly taking the state of the stock market into account in their evaluation of the economic climate and argued that in this context it is important to know whether observed fluctuations in stock prices reflect economic fundamentals or whether they are merely speculative.

We used a VAR model underpinned by a theoretical framework describing the relationship between Australian stock prices and the macroeconomy to generate a time-series for fundamental stock prices. to actual data. We found that observed share prices deviate substantially and significantly from their fundamental values for long periods of time (about four years) and that at the end of our sample period Australian share prices were overvalued by approximately $10 \%$. 


\section{REFERENCES}

Ackert, Lucy F. and Brian F. Smith, "Stock Price Volatility, Ordinary Dividends, and Other Cash Flows to Shareholders", Journal of Finance 58 (1993), 1147-1160.

Blanchard, O. J. and D. Quah (1989),'The Dynamic Effects of Demand and Supply Disturbances", American Economic Review, 79, 655-673.

Campbell, John Y. and John Ammer, "What Moves the Stock and Bond Markets? A Variance Decomposition for Long-Term Asset Returns", Journal of Finance 48 (1993), 3-37.

Campbell, John Y. and John H. Cochrane, "Force of Habit: A Consumption-Based Explanation of Aggregate Stockholder Behaviour", Journal of political Economy 107 (1999), 205-251.

Campbell, John Y., Andrew W. Lo and Craig MacKinlay, The Econometrics of FinancialMarkets (1997), Princeton University Press.

Campbell, John Y. and Robert J. Shiller, "Cointegration and Tests of Present Value Models", Journal of Political Economy 95 (1987), 1062-1088.

Campbell, John Y. and Robert J. Shiller, "Stock Prices, Earnings and Expected Dividends", Journal of Finance 43 (1988), 661-676.

Campbell, John Y. and Robert J. Shiller, "The Dividend-Price Ratio and Expectations of Future Dividends and Discount Factor", Review of Financial Studies 1 (1989), 195-228.

Campbell, J. Y. and R. J. Shiller (1998), "Valuation Ratios and the Long-Run Stock Market Outlook", Journal of Portfolio Management, 24, 11-26.

Chen, Nai-Fu, Richard Roll and Stephen A. Ross, "Economic Forces and the Stock Market", Joumal of Business 59 (1986), 383-403.

Cheung, Yin-Wong and Lilian K. Ng, "International Evidence on the Stock Market and Aggregate Economic Activity", Joumal of Empirical Finance 5 (1998), 281-296.

Chung, Heetaik and Bong-Soo Lee, "Fundamental and Nonfundamental Components in Stock Prices of Pacific-Rim Countries", Pacific-Basin Journal of Finance 6 (1998), 321-346.

Cochrane, John, "New Facts in Finance", Economic Perspectives (Federal Reserve Bank of Chicago), 23(3), Third quarter 1999, 36-58.

Cuthbertson, Keith, Simon Hayes and Dirk Nitzsche, "UK Stock Prices and Returns", Economic Journal, 107 (1997), 986-1008. 
Dickey, D. A. and W. A Fuller (1981), "Likelihood Ratio Statistics for Autoregressive Time Series with a Unit Root", Econometrica, 49, 1057-1072.

Gjerde, Oystein and Frode Saettem, "Causal Relations among Stock Returns and Macroeconomic Variables in a Small, Open Economy", Joumal of International Financial Markets, Institutions and Money 9 (1999), 61-47.

Gregory, Allan W. and Michael R. Veall, "Formulating Wald Tests of Non-Linear Restrictions", Econometrica 53 (1995), 1465-1468.

Hess, Patrick J. and Bong-Soo Lee, "Stock Returns and Inflation with Supply and Demand Disturbances", The Review of Financial Studies 12 (1999), 1203-1218.

Johansen, S. (1988), "Statistical Analysis of Cointegration Vectors", Journal of Economic Dynamics and Control, 12, 231-254.

Johansen, S. and K. Juselius (1990), "Maximum Likelihood Estimation and Inference on Cointegration - with Applications to the Demand for Money", Oxford Bulletin of Economics and Statistics, 52, 169-210.

Layard, Richard, Stephen Nickell and Richard Jackman, Unemployment: Macroeconomic Performance and the Labour Market (1991), Oxford University Press.

Lee, Bong-Soo, “Causal Relations among Stock Returns, Interest Rates, Real Activity and Inflation", Journal of Finance 47 (1992), 1591-1603.

Lee, Bong-Soo, "The Response of Stock Prices to Permanent and Temporary Dividend Shocks", Journal of Financial and Quantitative Analysis 30 (1995), 122.

Lee, Bong-Soo, "Permanent, Temporary and Non-Fundamental Components of Stock Prices", Joumal of Financial and Quantitative Analysis, 33 (1998), 1-32.

Macfarlane, Ian, "Statement by the Governor, Mr Ian Macfarlane: Monetary Policy", Media Release, Reserve Bank of Australia, 7 February, 2001.

Macfarlane, Ian, "Statement by the Governor, Mr Ian Macfarlane: Monetary Policy", Media Release, Reserve Bank of Australia, 7 March, 2001.

Macfarlane, Ian, "Statement by the Governor, Mr Ian Macfarlane: Monetary Policy", Media Release, Reserve Bank of Australia, 4 April, 2001.

Merton, Robert C., "An Intertemporal Capital Asset Pricing Model", Econometrica 41 (1973), 867-888.

Merton, Robert C. (1980), "On Estimating the Expected Return on the Market. An Exploratory Investigation”, Joumal of Financial Economics 8 (1980), 323-361. 
Table 1. - Summary Statistics

\begin{tabular}{|c|c|c|c|c|c|c|c|c|c|c|}
\hline Variable & Mean & St. Dev & Skewness & Kurtosis & $\mathrm{J}-\mathrm{B}$ & $\mathrm{AR}(1)$ & $\mathrm{AR}(2)$ & $\mathrm{AR}(3)$ & $\mathrm{AR}(4)$ & $Q(4)$ \\
\hline$\Delta \ln (\mathrm{AOP})$ & 0.022 & 0.081 & -1.186 & 3.923 & $\begin{array}{l}70.0468 \\
{[0.000]}\end{array}$ & $\begin{array}{l}0.2135 \\
(0.1118)\end{array}$ & $\begin{array}{l}-0.0775 \\
(0.1168)\end{array}$ & $\begin{array}{l}-0.0529 \\
(0.1174)\end{array}$ & $\begin{array}{l}-0.1542 \\
(0.1177)\end{array}$ & $\begin{array}{l}6.5795 \\
{[0.160]}\end{array}$ \\
\hline$\Delta \ln (\mathrm{AOA})$ & 0.032 & 0.090 & -2.241 & 11.073 & $\begin{array}{l}475.6180 \\
{[0.000]}\end{array}$ & $\begin{array}{l}0.04015 \\
(0.1118)\end{array}$ & $\begin{array}{l}-0.0475 \\
(0.1120)\end{array}$ & $\begin{array}{l}-0.0336 \\
(0.1122)\end{array}$ & $\begin{array}{l}-0.1514 \\
(0.1124)\end{array}$ & $\begin{array}{l}2.3991 \\
{[0.663]}\end{array}$ \\
\hline$\Delta \ln (\mathrm{CP})$ & 0.013 & 0.010 & 0.319 & -0.480 & $\begin{array}{l}2.1279 \\
{[0.345]}\end{array}$ & $\begin{array}{l}0.6673 \\
(0.1118)\end{array}$ & $\begin{array}{l}0.6212 \\
(0.1537)\end{array}$ & $\begin{array}{l}0.6234 \\
(0.1824)\end{array}$ & $\begin{array}{l}0.5517 \\
(0.2074)\end{array}$ & $\begin{array}{l}128.8135 \\
{[0.000]}\end{array}$ \\
\hline BB90 & 0.027 & 0.011 & 0.093 & -1.382 & $\begin{array}{l}6.6639 \\
{[0.036]}\end{array}$ & $\begin{array}{l}0.9526 \\
(0.1111)\end{array}$ & $\begin{array}{l}0.8867 \\
(0.1864)\end{array}$ & $\begin{array}{l}0.8298 \\
(0.2328)\end{array}$ & $\begin{array}{l}0.7586 \\
(0.2668)\end{array}$ & $\begin{array}{l}252.7854 \\
{[0.000]}\end{array}$ \\
\hline$\Delta \ln (\mathrm{RAOP})$ & 0.009 & 0.083 & -1.306 & 3.917 & $\begin{array}{l}73.8743 \\
{[0.000]}\end{array}$ & $\begin{array}{l}0.2097 \\
(0.1118)\end{array}$ & $\begin{array}{l}-0.0653 \\
(0.1166)\end{array}$ & $\begin{array}{l}-0.0235 \\
(0.1171)\end{array}$ & $\begin{array}{l}-0.1322 \\
(0.1171)\end{array}$ & $\begin{array}{l}5.5673 \\
{[0.234]}\end{array}$ \\
\hline$\Delta \ln (\mathrm{RAOA})$ & 0.019 & 0.091 & -2.332 & 11.153 & $\begin{array}{l}487.1610 \\
{[0.000]}\end{array}$ & $\begin{array}{l}0.04309 \\
(0.1118)\end{array}$ & $\begin{array}{l}-0.0410 \\
(0.1120)\end{array}$ & $\begin{array}{l}-0.0102 \\
(0.1122)\end{array}$ & $\begin{array}{l}-0.1304 \\
(0.1122)\end{array}$ & $\begin{array}{l}128.8135 \\
{[0.000]}\end{array}$ \\
\hline $\operatorname{RBB} 90\left(f_{t}\right)$ & 0.014 & 0.008 & 0.541 & 0.014 & $\begin{array}{l}3.6929 \\
{[0.158]}\end{array}$ & $\begin{array}{l}0.3460 \\
(0.1111)\end{array}$ & $\begin{array}{l}0.1976 \\
(0.1237)\end{array}$ & $\begin{array}{l}0.3613 \\
(0.1275)\end{array}$ & $\begin{array}{l}0.3413 \\
(0.1396)\end{array}$ & $\begin{array}{l}34.8087 \\
{[0.000]}\end{array}$ \\
\hline$\Delta \operatorname{lnRGDP}$ & 0.009 & 0.009 & -0.164 & 1.171 & $\begin{array}{l}4.9287 \\
{[0.085]}\end{array}$ & $\begin{array}{l}0.2037 \\
(0.1118)\end{array}$ & $\begin{array}{l}0.1554 \\
(0.1164)\end{array}$ & $\begin{array}{l}0.1135 \\
(0.1189)\end{array}$ & $\begin{array}{l}-0.2121 \\
(0.1203)\end{array}$ & $\begin{array}{l}10.4544 \\
{[0.033]}\end{array}$ \\
\hline$V_{t}$ & 0.005 & 0.007 & 2.422 & 6.036 & $\begin{array}{l}7.4147 \\
{[0.025]}\end{array}$ & $\begin{array}{l}-0.0022 \\
(0.1118)\end{array}$ & $\begin{array}{l}0.3216 \\
(0.1118)\end{array}$ & $\begin{array}{l}0.0466 \\
(0.1228)\end{array}$ & $\begin{array}{l}0.0384 \\
(0.1230)\end{array}$ & $\begin{array}{l}9.0109 \\
{[0.061]}\end{array}$ \\
\hline$\pi_{t}$ & 4.595 & 0.158 & 0.228 & 1.419 & $\begin{array}{l}7.4147 \\
{[0.025]}\end{array}$ & $\begin{array}{l}0.8617 \\
(1.1111)\end{array}$ & $\begin{array}{l}0.6755 \\
(2.1750)\end{array}$ & $\begin{array}{l}0.5050 \\
(3.2050)\end{array}$ & $\begin{array}{l}0.3430 \\
(4.2200)\end{array}$ & $\begin{array}{l}133.5028 \\
{[0.000]}\end{array}$ \\
\hline$\Delta \mathrm{q}_{\mathrm{t}}$ & 0.009 & 0.009 & -0.164 & 1.171 & $\begin{array}{l}3.9585 \\
{[0.138]}\end{array}$ & $\begin{array}{l}0.2037 \\
(1.1118)\end{array}$ & $\begin{array}{l}0.1554 \\
(2.1164)\end{array}$ & $\begin{array}{l}0.1135 \\
(3.1189)\end{array}$ & $\begin{array}{l}-0.2121 \\
(4.1203)\end{array}$ & $\begin{array}{l}10.4544 \\
{[0.033]}\end{array}$ \\
\hline
\end{tabular}

Notes: (1) AOP = All Ordinaries Price Index, AOA = All Ordinaries Accumulation Index, CPI =Consumer Price Index, $\mathrm{BB90}=90$-day bank-accepted bill rate, RAOP $=$ AOP deflated by the CPI, RAOA $=$ AOA deflated by the CPI, RBB90 $=\mathrm{BB} 90$ less the inflation rate, $\mathrm{RGDP}=\mathrm{Real}$ Gross Domestic Product, $\mathrm{V}=$ variance of real share returns, $\pi=\log$ stock-price-output ratio, $q=\log$ scaled RGDP. (2) Both skewness and excess-kurtosis statistics are N(0,1). (3) The J-B statistic is the Jarque-Bera statistic for a test of normality and is distributed $\chi^{2}$ with two degrees of freedom under the null of normality. Figures in brackets below the statistics are prob values. (4) The AR

statistics are first- to fourth-order autocorrelation coefficients with standard errors in parentheses. (5) The Q statistic is the Ljung-Box-Pierce portmanteau statistic for first- to fourth-order autocorrelation. Figures in brackets are prob values. 
Table 2. - Stationarity of $p$ and $q$

\begin{tabular}{|c|c|c|c|c|}
\hline & \multicolumn{2}{|c|}{$\mathbf{q}$} & \multicolumn{2}{|c|}{$p$} \\
\hline & Test Statistic: No trend & Test Statistic: Trend & Test Statistic: No trend & Test Statistic: Trend \\
\hline DF & 1.0134 & -1.4626 & -0.7620 & -2.4677 \\
\hline $\mathrm{ADF}(1)$ & 0.6453 & -1.9131 & -1.2120 & -3.0323 \\
\hline $\mathrm{ADF}(2)$ & 0.4920 & -2.3121 & -1.0373 & -2.8650 \\
\hline $\mathrm{ADF}(3)$ & 0.4386 & -2.5938 & -1.0716 & -3.0162 \\
\hline $\mathrm{ADF}(4)$ & 0.7585 & -1.8119 & -0.8096 & -2.7155 \\
\hline
\end{tabular}

Notes: (1) $\mathrm{p}=$ real share price, $\mathrm{q}=$ scaled real output. (2) DF is the Dickey-Fuller statistic and ADF(i) is the augmented Dickey-Fuller statistic with lag i. The 95\% critical value for $\mathrm{DF}$ and $\mathrm{ADF}$ is -2.8996 for the case where there is no trend term in the $\mathrm{DF}$ equation and -3.4688 for the case where a trend term is included. 
Table 3. - Cointegration of $p$ and $q$

\begin{tabular}{|c|c|c|c|c|c|c|c|c|}
\hline Test & VAR order & Trend & $\mathrm{H}_{0}$ & $\mathbf{H}_{\mathbf{A}}$ & Statistic & $95 \% \mathrm{cv}$ & $90 \% \mathrm{cv}$ & Cointegrating Vector \\
\hline \multirow[t]{2}{*}{ Max Eigenvalue } & 1 & No & $r=0$ & $r=1$ & 17.263 & 14.88 & 12.98 & \\
\hline & & & $\mathrm{I}<=1$ & $r=2$ & 0.547 & 8.07 & 6.5 & -1.000 \\
\hline \multirow[t]{2}{*}{ Trace } & 1 & No & $\mathrm{r}=0$ & $\mathrm{r}>=1$ & 17.810 & 17.86 & 15.75 & 1.044 \\
\hline & & & $\mathrm{r}<=1$ & $r=2$ & 0.547 & 8.07 & 6.5 & \\
\hline \multirow[t]{2}{*}{ Max Eigenvalue } & 1 & Yes & $I=0$ & $r=1$ & 23.518 & 18.33 & 16.28 & \\
\hline & & & $\mathbf{r}<=1$ & $\mathrm{r}=2$ & 7.027 & 11.54 & 9.75 & -1.000 \\
\hline \multirow{2}{*}{ Trace } & 1 & Yes & $\mathrm{r}=0$ & $\mathrm{r}>=1$ & 30.545 & 23.83 & 21.23 & 5.234 \\
\hline & & & $\mathrm{r}<=1$ & $r=2$ & 7.027 & 11.54 & 9.75 & \\
\hline \multirow[t]{2}{*}{ Max Eigenvalue } & 2 & No & $\mathrm{r}=0$ & $\mathrm{I}=1$ & 13.589 & 14.88 & 12.98 & \\
\hline & & & $\mathrm{r}<=1$ & $r=2$ & 0.498 & 8.07 & 6.5 & -1.000 \\
\hline \multirow{2}{*}{ Trace } & 2 & No & $r=0$ & $r>=1$ & 14.086 & 17.86 & 15.75 & 1.096 \\
\hline & & & $\mathrm{r}<=1$ & $r=2$ & 0.498 & 8.07 & 6.5 & \\
\hline \multirow[t]{2}{*}{ Max Eigenvalue } & 2 & Yes & $\mathrm{r}=0$ & $\mathrm{r}=1$ & 18.328 & 18.33 & 16.28 & \\
\hline & & & $\mathrm{T}<=1$ & $I=2$ & 5.153 & 11.54 & 9.75 & -1.000 \\
\hline \multirow[t]{2}{*}{ Trace } & 2 & Yes & $\mathrm{r}=0$ & $\mathrm{r}>=1$ & 23.482 & 23.83 & 21.23 & 4.870 \\
\hline & & & $\mathrm{r}<=1$ & $\mathrm{r}=2$ & 5.153 & 11.54 & 9.75 & \\
\hline
\end{tabular}

Notes: (1) the values in the Statistic column are the values of Johansen's maximum eigenvalue and trace statistics for cointegration. (2) The cointegrating vector is estimated using Johansen's MLE procedure and reported nomalised on the coefficient of $\mathrm{p}$. 
Table 4. - Stationarity of VAR variables

\begin{tabular}{|c|c|c|c|c|c|c|c|c|}
\hline & \multicolumn{2}{|c|}{$\pi_{t}$} & \multicolumn{2}{|c|}{$\Delta q_{t}$} & \multicolumn{2}{|c|}{$\overline{f_{t}}$} & \multicolumn{2}{|c|}{$V_{t}$} \\
\hline & No trend & Trend & No Trend & Trend & No Trend & Trend & No Trend & Trend \\
\hline $\mathrm{DF}$ & -2.3741 & -2.7168 & -6.5774 & -6.6866 & -5.9102 & -6.4827 & -8.3734 & -9.5930 \\
\hline $\mathrm{ADF}(1)$ & -3.0522 & -3.3905 & -4.6544 & -4.7664 & -4.3231 & -4.9028 & -4.2291 & -5.0929 \\
\hline $\operatorname{ADF}(2)$ & -2.8397 & -3.1727 & -3.8292 & -3.9497 & -2.6181 & -3.1587 & -3.4862 & -4.3878 \\
\hline $\operatorname{ADF}(3)$ & -2.9438 & -3.2652 & -4.6998 & -4.8701 & -1.9155 & -2.4612 & -3.4306 & -4.5217 \\
\hline $\mathrm{ADF}(4)$ & -2.6701 & -2.9926 & -3.8289 & -4.0075 & -1.9360 & -2.4676 & -3.1210 & -4.3281 \\
\hline
\end{tabular}

Notes: (1) $\pi=\log$ stock-price-output ratio, $q=\log$ scaled RGDP, $\mathrm{f}=$ real 90-day bill rate and $\mathrm{V}=$ variance of real share returns. (2) DF is the Dickey-Fuller statistic and $\mathrm{ADF}(\mathrm{i})$ is the augmented Dickey-Fuller statistic with lag $\mathrm{i}$. The $95 \%$ critical value for $\mathrm{DF}$ and $\mathrm{ADF}$ is -2.8996 for the case where there is no trend term in the DF equation and -3.4688 for the case where a trend term is included. 
Table 5. - VAR Statistics and Tests for the OLS estimation of the Constant Return Present Value Model

$$
z_{t+1}=A z_{t}+\varepsilon_{t+1}
$$

\begin{tabular}{ccccc}
\hline $\boldsymbol{z}_{t+1}$ & $\boldsymbol{a}_{i 1}$ & $\boldsymbol{a}_{i 2}$ & $\mathbf{R}^{2}$ & $\mathbf{Q}(4)$ \\
\hline$\pi_{t}$ & 0.870 & -0.075 & 0.750 & 6.035 \\
& $(14.402)$ & $(-0.071)$ & $0.197)$ & 7.630 \\
$\Delta q_{t}$ & 0.019 & 0.088 & 0.132 & $(0.106)$ \\
& $(2.872)$ & $(0.779)$ & & \\
\hline
\end{tabular}

Wald Statistic $=119.974(0.000)$

Notes: (1) $\pi_{t}$ is the log output-share-price ratio and $\Delta q_{t}$ is output growth. (2) The model was estimated using OLS and the figures below the estimated coefficients are the tstatistics. (3) $a_{i j}$ are the elements of the coefficient matrix $A$. (4) The Q(4) statistic is the Ljung-Box-Pierce test statistic for joint significance of the first four autocorrelation coefficients. Figures in parentheses below the Q(4) statistic are marginal significance levels. (5) The Wald statistic corresponds to a test of the restrictions in equation (15) using a value for $\mu$, the linearisation parameter, of 0.99093 . The marginal significance level appears in parentheses after the reported Wald statistic. 
Table 6. - VAR Statistics and Tests for the OLS Estimation of the Time-Varying Risk-Free Present Value Model

$$
z_{t+1}=A z_{t}+\varepsilon_{t+1}
$$

\begin{tabular}{|c|c|c|c|c|c|}
\hline$z_{t+1}$ & $a_{i 1}$ & $a_{i 2}$ & $a_{i 3}$ & $\mathbf{R}^{2}$ & $\mathbf{Q}(4)$ \\
\hline$\pi_{t}$ & $\begin{array}{c}0.869 \\
(14.445)\end{array}$ & $\begin{array}{c}-0.0852 \\
(-0.081)\end{array}$ & $\begin{array}{c}-0.916 \\
(-0.780)\end{array}$ & 0.752 & $\begin{array}{c}5.751 \\
(0.219)\end{array}$ \\
\hline$\Delta q_{t}$ & $\begin{array}{c}0.0183 \\
(2.900)\end{array}$ & $\begin{array}{c}0.085 \\
(0.772)\end{array}$ & $\begin{array}{c}-0.213 \\
(-1.729)\end{array}$ & 0.164 & $\begin{array}{c}6.376 \\
(0.173)\end{array}$ \\
\hline$f_{t}$ & $\begin{array}{c}-0.003 \\
(-0.464)\end{array}$ & $\begin{array}{c}-0.019 \\
(-0.206)\end{array}$ & $\begin{array}{c}0.340 \\
(3.217)\end{array}$ & 0.120 & $\begin{array}{l}10.181 \\
(0.037)\end{array}$ \\
\hline
\end{tabular}

Wald Statistic $=75.331(0.000)$

Notes: (1) $\pi_{t}$ is the log output-share-price ratio, $\Delta q_{t}$ is output growth and $f_{t}$ is the real risk-free rate. (2) The model was estimated using OLS and the figures below the estimated coefficients are the t-statistics. (3) $a_{i j}$ are the elements of the coefficient matrix $A$. (4) The Q(4) statistic is the Ljung-Box-Pierce test statistic for joint significance of the first four autocorrelation coefficients. Figures in parentheses below the $Q(4)$ statistic are marginal significance levels. (5) The Wald statistic corresponds to a test of the restrictions in equation (22) using a value of $\mu$, the linearisation parameter, of 0.99093 . The marginal significance level appears in parentheses after the reported Wald statistic. 
Table 7. - VAR Statistics and Tests for the OLS Estimation of the Time-Varying Risk Present Value Model *

$$
z_{t+1}=A z_{t}+\varepsilon_{t+1}
$$

\begin{tabular}{|c|c|c|c|c|c|c|}
\hline$Z_{t+1}$ & $a_{i 1}$ & $a_{i 2}$ & $a_{i 3}$ & $\mathrm{R}^{2}$ & $\mathrm{Q}(4)$ & $\begin{array}{c}\text { CRRA } \\
\alpha\end{array}$ \\
\hline$\pi_{\mathrm{t}}$ & $\begin{array}{c}0.878 \\
(14.996)\end{array}$ & $\begin{array}{c}-0.247 \\
(-0.242)\end{array}$ & $\begin{array}{c}-2.875 \\
(-2.315)\end{array}$ & 0.766 & $\begin{array}{c}3.976 \\
(0.409)\end{array}$ & 1.1235 \\
\hline$\Delta q_{\mathrm{t}}$ & $\begin{array}{c}0.019 \\
(2.880)\end{array}$ & $\begin{array}{c}0.086 \\
(0.762)\end{array}$ & $\begin{array}{c}-0.028 \\
(-0.205)\end{array}$ & 0.133 & $\begin{array}{c}7.249 \\
(0.123)\end{array}$ & \\
\hline$V_{\mathrm{t}}$ & $\begin{array}{c}0.006 \\
(1.226) \\
\end{array}$ & $\begin{array}{c}-0.092 \\
(-1.001) \\
\end{array}$ & $\begin{array}{c}-0.014 \\
(-0.126) \\
\end{array}$ & 0.023 & $\begin{array}{c}8.939 \\
(0.063) \\
\end{array}$ & \\
\hline
\end{tabular}

\section{Wald Statistic $=197.321(0.000)$}

Notes: (1) $\pi_{t}$ is the log output-share-price ratio and $\Delta q_{t}$ is output growth. (2) The model was estimated using OLS and the figures below the estimated coefficients are the tstatistics. (3) $a_{i j}$ are the elements of the coefficient matrix $A$. (4) The Q(4) statistic is the Ljung-Box-Pierce test statistic for joint significance of the first four autocorrelation coefficients. Figures in parentheses below the Q(4) statistic are marginal significance levels. (5) The Wald statistic corresponds to a test of the restrictions in equation (25) using a value for $\mu$, the linearisation parameter, of 0.99093 and a value for the CRRA reported in the CRRA column of the table. The marginal significance level appears in parentheses after the reported Wald statistic. 
